\title{
The role of an academic library in research: researchers' perspectives at a South African University of Technology
}

\author{
Genevieve Hart' and Lynn Kleinveldt ${ }^{2}$ \\ Department of Library and Information Science, University of the Western Cape \\ ghart@uwc.ac.za; Kleinveldt@cput.ac.za
}

\begin{abstract}
Received: 10 April 2011
Accepted: 5 May 201I

Academic libraries typically identify research support as a central pillar in their mission. But they need to examine how their mission statements relate to the perspectives of researchers themselves, especially in view of reported changes in researchers' information seeking and sharing in the online environment. By means of a questionnaire survey of 102 full time academic staff at the Cape Peninsula University of Technology, the project examined how researchers use their institution's library in their research and what their expectations are. For various historical reasons universities of technology lag behind in terms of their research output and in recent years CPUT has prioritised research. This is reflected in the virtual unanimity among the 102 respondents that research is essential to their job despite their heavy teaching loads. Overall, the study finds that most (over 65\%) continue to rely on the library for access to print and electronic resources. It finds a heavy emphasis on the traditional functions of an academic library, such as resource and information management. A few gaps emerge between the delivery of library services and researchers' desires. For example, very few attend the library's scheduled database training workshops; yet most see database training as one of the library's key contributions to research. The most pressing desire is to be kept informed of new research in their fields; yet only a minority experience this level of service and less than half express confidence in the discipline knowledge of librarians.
\end{abstract}

Keywords: South Africa; universities of technology; research; academic libraries

\section{Introduction}

This article reports on an investigation of the role of an academic library in research which was conducted by means of a questionnaire survey of academics at the Cape Peninsula University of Technology (CPUT) in Cape Town. Academic libraries typically identify research support as a central pillar in their mission; but they need to examine how their mission statements relate to the perspectives of researchers themselves. So the starting point of the research project was the wish to find out how researchers use their institution's library in their research, what they expect of it and how their expectations are being met.

The project is framed by two sets of factors: the impact of ICTs on researchers' information seeking and use; and the pressure on South African universities of technology to increase their research standing. According to the findings of a major survey of researchers in the United Kingdom in 2007, the rise of desktop access to digital information is "testing" the relationship between researchers and libraries (Brown \& Swan 2007: 4). For example, in 200I 40\% of researchers in the UK personally visited their main institutional library at least once a week but by 2006 this number had dropped to $22.5 \%$. More evidence of the "testing" of the relationship lies in the series of faculty surveys conducted in the United States by the Ithaka organization since 2000 which has documented the growing insignificance of libraries in the information seeking or "discovery" of researchers in many disciplines (Schonfeld \& Housewright 2010: 2). However, although some library functions are in danger of becoming redundant in the online environment, research shows that others are increasing in importance. An example is the survey of researchers at Purdue University in which respondents kept returning to their problems with organizing, describing data and archiving data (Brandt 2007: 365). These are the longstanding competencies of librarians.

The choice of CPUT as research site was motivated by its stated resolve to improve its standing from a "tuition-based vocational" technikon to a fully fledged university with a strong research mandate (Weintrob 20II). And indeed, its research output has increased dramatically in recent years. It is of interest to see if the library is perceived by CPUT researchers as playing a part in this transition.

\section{Background}

Universities account for $19.9 \%$ of South Africa's research and development (R\&D) - compared with $58.6 \%$ from business and 20.4\% from government (including the research councils) (Department of Science \& Technology 20I0: 20).

I. Genevieve Hart (PhD) is Associate Professor in the Department of Library and Information Science University of the Western Cape, South Africa.

2. Lynn Kleinveldt is a Faculty Librarian: Applied Sciences and Health and Wellness at the Cape Peninsula University of Technology Libraries (Cape Town Campus), South Africa. 
Research production in South African universities is measured according to the internationally accepted performance indicators of number and quality of peer-reviewed publications, throughput and quality of postgraduate students, income generated through grants and contracts, and the standing of their researchers as evidenced in National Research Foundation (NRF) rating.

Research has been defined as "creative work undertaken on a systematic basis in order to increase the stock of knowledge, including knowledge of man, culture and society, and the use of this stock of knowledge to devise new applications" (Frascati Manual 2002: 30). A key attribute of the leading knowledge societies is the value they give to research. In 2008 the South African government's expenditure on research and development (R\&D) was $0.92 \%$ of GDP, compared with 3.75\% in Sweden (the highest ranking), I.44 in China, 0.80 in India (Department of Science \& Technology 2010: 13). Government has identified research as a national imperative and has promised to increase its $R$ and $D$ expenditure to $1.5 \%$ of GDP by 2014. Research in science and technology is crucial to the sustainable development required if South Africa is to compete in the global knowledge economy. And research in the social sciences and humanities provides insight into and solutions to our social, economic and political challenges. Apart from increasing the overall amount of research, there are two critical priorities in South Africa's research strategising: to redress past inequalities and to strengthen and diversify research capacity (Blaine 20I0). As the existing cadre of researchers reaches retirement age (Research Libraries Consortium 2007), there is an urgent need to increase the numbers of young and black researchers.

As one of the six new universities of technology (UoT), CPUT is expected to contribute to the national agenda of innovation, technology transfer and international competitiveness (Du Pré 2009: 6). In the report by the South African Technology Network's task team on the nature and role of UoTs, Du Pré (2009: xi) argues that their specific mission is to make knowledge "useful" and that they should take the lead in applied technological research that will contribute to sustainable development. However, UoTs are relatively "new kids on the research block" and still have to negotiate their particular place in the higher education landscape. They came into being in 2005 to replace the Technikons, which had replaced the Colleges for Advanced Technical Education in the late 1970s. The changes represent more than mere name changes. The UoTs still claim to provide an education more closely applicable to the workplace than traditional universities, but they are expected to take on the responsibilities of universities and change their longstanding image as "glorified high schools" (Masumerule 2005; Du Pre 2009: 59).

Research output, in the form of scholarly publication, is central to this desired change in image, but is dependent on the growth of a research culture among academic staff. A glance at the research output of all 25 SA universities in 2009 reveals the challenges facing the UoTs. All six fall in the bottom 10 of the rankings and account for only $4.1 \%$ of the total output of scholarly publication in that year - compared with the $13 \%$ of the leading research institution, the University of Cape Town. But Du Pré (2009: 37) would point out the injustice in such comparison. The UoTs have inherited huge backlogs in research infrastructure. The leading research universities in South Africa, all so-called historically advantaged institutions, have deep research reserves, thanks to their research subsidies from government over many decades.

Sadly, the higher education sector in South Africa is still marked by apartheid-era disparities. So, another factor that has to be taken into account in examining research output rankings is "historical disadvantage". Apart from the UoTs, the other lowly ranked performers are all historically disadvantaged institutions, established in the "homelands" to serve apartheid ideology. Some UoTs, like CPUT, have to contend with not only their historical roots in technical vocational colleges but also their history as systematically under-resourced institutions. The so-called "size and shape" restructuring process between 1999 and 2005 reduced numbers of higher education institutions from 36 to 25 by means of mergers. The mergers hoped to overcome disparities by cutting across historical divides but Du Pré (2009: 16) argues that the mergers in fact hampered the progress of the UoT sector as many UoTs had new issues thrust upon them, such as the building of new institutional cultures across scattered and unevenly resourced campuses. Thus, CPUT, the outcome of the merger of the Cape Technikon, a historically white or advantaged institution, and the Peninsula Technikon, a historically black or disadvantaged institution, is spread across ten campuses.

The vision statements of CPUT reflect the UoT task team report that was mentioned earlier, as shown in its desire "to be at the heart of technology and education and innovation in Africa" (Cape Peninsula University of Technology 2006). Its mission is "to develop and sustain an empowering environment where, through teaching, learning, research and scholarship, our students and staff, in partnership with the community and industry, are able to create and apply knowledge that contributes to development". CPUT has prioritised its research programmes and by 2008 led the other UoTs in terms of research output. Even though still not matching national benchmarks, from 2004 to 2009 its number of accredited journal articles more than doubled (from 40.88 units to I0I.8I) (Van Aswegen 20I0: 2). In an interview for the university online newsletter, the Deputy ViceChancellor for Research attributes the achievements to the establishment of two units, the Technology Transfer Office and the Centre for Postgraduate Studies (Weintroub 20II). He also 
acknowledges the contribution of several internal support services, including the library, which he says offer indispensable support to CPUT research.

According to its mission statement, CPUT's library is a "partner" in the academic mission and at its centre. It aims to be "the hub of innovative and highly valued knowledge systems, services and resources for its clients, as the information partner at the centre of CPUT's academic mission" (Coetzee, 2007: I). In response to the university's drive to improve its research output, the library has undertaken two initiatives in the last few years: the Research Information Support Centre (RISC), a unit in the library designed to serve postgraduate students; and the fledgling institutional repository, the Digital Knowledge Research Repository.

In the light of the library's mission statement, the project described in this article set out to explore academic staff's perceptions of the library in terms of their research. The underlying question is: Do they share the view that the library is a partner in their research work? It is hoped that this paper will contribute some insight into how UoT libraries might enhance their research support.

\section{Academic libraries' role in research}

A survey of the research and professional literature on the role of academic libraries in research reveals three, often interconnected, themes:

- the information needs and information-seeking behaviour of researchers - often reports of surveys of researchers' use of libraries;

- descriptions of library roles and services in the support of research - some accompanied by surveys of users of these services; and

- lists of competencies of so-called research librarians produced by professional library associations such as the Association of Southeastern Research Libraries (200I) and the Canadian Association of Research Libraries (20I0).

A useful overview of existing research across all three themes is provided in Webb, Gannon-Leary and Bent's book, Providing Useful Library Services for Research (2007).

\subsection{Researchers' expectations and experiences of libraries}

Several studies set out to document how researchers use libraries, usually by means of questionnaire surveys and interviews. Some focus on researchers' use of specific resources such as electronic journals (for example Mgobozi and Ocholla 2002; Ortiz-Repiso, Bazán, Ponsati, Cottereau 2006) and others focus on a specific field such as agriculture (for example Dulle, Lwehabura, Mulimila \& Mato 200I). The studies provide a fairly consistent picture of what researchers require of their libraries, for example:

- access to up-to-date and generous collections of both print and electronic resources;

- access to archives and special collections - facilitated in recent years by libraries' digitisation projects ;

- efficient ICTs;

- quick document delivery services; and

- specialist help and advice in tracing resources.

The UK report Researchers' Use of Academic Libraries and Their Services (Brown \& Swan 2007), commissioned by the Research Information Network and Consortium of Research Libraries, is perhaps the most comprehensive of these studies. It documents present use by means of a survey of 2250 researchers in all disciplines and 300 librarians; identifies the key roles libraries play in research; and explores the changes in researcher behaviour that might impact on libraries in future. The report concludes that, while most researchers are satisfied that their libraries are providing them with the information they need, the role of libraries in research is in danger of being "diluted" (Brown \& Swan 2007: 3). Challenges to their role come from the rise of virtual research communities, the increase in interdisciplinary work and crossinstitutional collaboration, and researchers' use of social networking space to share information. The report finds that the great majority of researchers:

- use digital finding aids at their desktops to find both digital and printed resources - explaining the drop in physical visits to the library that was mentioned in the introduction;

- adopt a variety of pragmatic approaches to overcoming barriers to access, often bypassing the library - explaining recent declines in formal inter-library lending; and

- make increasing use of informal electronic mechanisms for sharing information among themselves.

Some implications for libraries are clear. For example the sharing of resources across libraries must be made easier and their role in managing the increasing volumes of digital research output should be clarified (Brown \& Swan 2007: 42).

The Ithaka survey of over 3000 American academics in 2009, the most recent in a series of surveys since 2000 , examines key strategic issues for academic information services (Schonfeld \& Housewright 20I0). It takes a broader view 
than the UK survey as it looks at academics' scholarly communication, not just library use, and it places research support within the context of the other functions of an academic library. It asked its respondents to rank the five roles of an academic library, as gateway, archive, buyer, support of teaching and support of research, and finds that they rank the role of buyer far more strongly than the other four roles. The role as archive or repository follows; then the other three come close together (p. 10). The gateway role, traditionally a core function of academic libraries, has diminished in importance with the rise of other online services. Indeed, the authors argue that libraries as starting points in information seeking have already "lost" researchers in the sciences and in some of the social sciences and that researchers in the humanities will follow them soon.

The study echoes the UK RIN study in its uncovering of gaps between researchers' perceptions and librarians'. Despite all the efforts of libraries to move beyond their traditional resource management roles, it seems that academics still value their "infrastructural" role, the management of collections (print and digital), far more than their roles in teaching and research. However, the finding that researchers in smaller more teaching-oriented universities value both the teaching and research support roles of their libraries more highly than those in the largest research universities might be significant for South African university libraries. The Ithaka authors argue that for teaching oriented academics the two functions are intertwined and suggest that the future of academic libraries lies in an even mix of teaching, learning and research services. Their print collections might move from expensive central locations; but libraries will evolve into collaborative electronic hubs or information commons for learning and research (Schonfeld \& Housewright 2010: 9).

A smaller scale Australian study at the Charles Sturt University involved interviews with just three public policy researchers and claims to go inside the heads of researchers, aiming to avoid librarians' preconceptions of what researchers need (Miller 2008). Its key insight is the need to be aware of how information needs and information behaviours vary according to the different phases of a research project. At the proposal development stage researchers need, for example, information on research funding opportunities, knowledge of authors and researchers in the area of interest, and personal interaction with academic colleagues to develop their research questions. The study identifies a number of motivating and demotivating factors. Some of these might be viewed as out of the reach of libraries, such as the desire for reliable research assistants and for a network of contacts outside the immediate organization to engage in informal sharing of research issues. However, others might be relevant, for example:

- the need to keep up-to-date with the latest developments in the areas of interest and for help in subscribing to personal electronic alerting services; and

- the time needed to learn how to use electronic databases and the re-learning required when they change from year to year.

The research in researchers' views and behaviours provides insight for librarians wishing to improve their research support services and programmes. Librarians need to recognise that different disciplines or domains have different requirements and that the expectations of senior established researchers might well differ from those of young PhD students. Librarians might also benefit from Miller's insights into how needs change in the course of a project. The research also perhaps highlights the need to develop the information literacy of researchers and the "research literacy" of librarians.

\subsection{Library services and collection development in the support of research}

Another focus in the literature is the services in libraries which are specifically aimed at supporting research. Typical of these are the studies that survey libraries' websites to examine programmes aimed at researchers (for example Fan 2005; Garner 2006; Hamblin 2008). The studies of researchers' needs, reported in the previous section, highlight the fundamental importance to research of generous access to current and archival collections, both print and electronic. There is some comment that collections in the developing world are lacking and that access is made difficult by a lack of cooperation and resource sharing (for example Dulle et al 200I; Van Zijl 2005). Van Zijl's comparison of research collection policy and procedures across two UoTs, one in New Zealand and the other in South Africa, found, for example, the South African institution to be lagging behind international standards.

The two recent and comprehensive UK surveys of libraries' research services by the Research Information Network (RIN) are of particular value. The investigation in 2007, which was mentioned above, provides some interesting insights into gaps between researchers' and librarians' views on the possible research roles of a library in the following five years. Respondents were asked to choose from 13 options. Seven areas of library expertise emerge as key responsibilities from researchers' responses: custodian of collections, repository manager, administrator of information management, subjectbased information expert, teacher of information management skills, dataset manager and technology specialist (Brown \& Swan 2007: 43-46). The librarian respondents agree on these but add others such as information literacy education, 
advising on intellectual property issues, and managing metadata. It seems, moreover, that they value their role as teaching research skills and disseminating research findings more highly than do researchers.

The focus of RIN's later investigation in 2010, The Value of Libraries for Research and Researchers: a RIN and RLUK Report (20I I), shifted from researchers' information behaviour to the documenting of the value of and return on investment of academic libraries in the UK. This largely qualitative study provides evidence of the links between specific library attributes and a university's research standing. Eleven library characteristics are found to be significant in, for example, increasing research income, recruiting high quality researchers and motivating researchers. Among the library attributes found to be crucial are information and organisational skills, good subject expertise, proactive information specialists, strong service culture, strong research collections and leadership in managing institutional repositories. Perhaps the most important attribute for the future of academic libraries, and yet the most intangible, is the belief among an institution's researchers in the academic library as a cornerstone of scholarship (p. 60).

There are library initiatives that aim to move proactively into the domain of researchers by establishing dedicated research units, which aim to "embed" the library in research activity. An example is that at the Curtin University of Technology which aims to "proactively support research activities by providing relevant resources, strengthening research processes, facilitating scholarly communication and promoting research output” (Garner 2006). Some of the activities taking place in these units are:

- managing the submission of electronic theses;

- managing institutional repositories;

- developing research collections;

- training in database searching;

- providing reading rooms for researchers away from the hurly-burly of the undergraduate library;

- building relationships across universities' research communities, for example between offices of research and development and the committees for postgraduate studies;

- setting up communication and collaboration tools for research communities such as wikis;

- locating librarians' offices in the faculties to ensure maximum contact with researchers and postgraduate students; and

- establishing online research portals, which offer seamless access to the vast array of e-resources (Hamblin 2005: 29).

Examples of similar South African initiatives come from the Research Libraries Consortium project begun in 2007 by the libraries of the universities of Cape Town, Kwazulu-Natal and the Witwatersrand, with financial support from the Carnegie Corporation. (A second project involving three more South African universities is to follow.) The Consortium points out that, because South African researchers often lack confidence, experience, and skills, they need more than sophisticated access to content (Research Libraries Consortium 2007). The project has three parts: the building of an online research portal, the creation of a Research Commons or dedicated research unit, in each of the three libraries, and the education of librarians in research skills. The Research Commons acts as a "one-stop shop" for postgraduates and academic staff who need assistance with research. The third component, the so-called "academy", addresses the issue of what was called above librarians' "research literacy". It consists of an intensive programme for selected library staff which might address the gap between librarian and researcher identified by the Research Information Network and Consortium of Research Libraries in 2007 , as mentioned earlier. The academy assumes that to gain credibility among researchers librarians need knowledge in two areas: research processes and methodologies; and subject or discipline knowledge adequate to enable effective communication with the researchers they serve. To build this knowledge, a week-long course is offered in which leading researchers across the disciplines speak and which prepares the librarian participants to conduct their own research.

\subsection{Librarians' competencies for research support}

The Canadian Association of Research Librarians (CARL) provides a useful analysis of the competencies of academic librarians that it believes might well apply in all technologically advanced countries. It argues that, while the essential role of an academic librarian has not changed, namely to bring together information seekers and information sources, dramatic changes in the environment oblige libraries to reassess their role (Canadian Association of Research Libraries 2010: 4). The association identifies seven sets of competencies, all of which relate more or less directly to research support in an "intense" and "constantly evolving" academic research environment" (Canadian Association of Research Libraries 2010: 3):

- foundational knowledge: of librarianship, the higher education environment, scholarly communications, and legal issues like copyright and licensing models;

- collections development: including digital curation, preservation of collections and archives, managing records;

- information literacy: including knowledge of learning models and strategies, reference services, engaging with and

SA Jnl Libs \& Info Sci 20II, 77(I) 
educating patrons;

- professional development and research: undertaking research, knowledge of the research process and the fundamentals of research methods;

- information technology skills: for example in emerging web technology, institutional repositories, database management;

- interpersonal skills: advocacy skills, enabling the required collaborations with diverse groups, writing and speaking skills; and

- leadership: including strategising to develop collaborations and partnerships with relevant communities.

The last two sets of competencies in the list refer to the building of relationships between researchers and librarians. As the following extract from Webb, Gannon-Leary and Bent's (2007: 130) survey of libraries' research services points out, libraries cannot assume that researchers know about their services:

While it is vital to listen to researchers and ensure that the library responds to their needs, we must do more than listen and react. Many researchers are unaware of the potential services and resources available to them and will only ask for what they already know about. This ignorance could easily compromise the quality of the research output. How much better might their research have been if they had been better informed?.

The CPUT research study did not directly assess CPUT librarians' competencies. However, the survey of researchers' library experiences might well provide insights useful in the enhancement of services.

\section{Research project questions and methodology}

The project investigated CPUT's academic staff use of and perceptions of the academic library in conducting their research. It is accepted that academics traditionally visit the library to browse the shelves, do inter-library loan requests, and consult librarians over book orders. But it seems from the international research that the role of the library as a "place" in researchers' working lives has changed. The purpose of the CPUT study was to ask what researchers need, want and expect from an academic library.

The study began with an in-depth interview with the manager of the library's Research Information Support Centre (RISC), who was assumed to be able to provide an accurate picture of the library's research services. This interview, as well as the survey of existing research, outlined above, informed the design of the questionnaire used in the survey of academic staff that followed. The questionnaire has four sections: the first collects personal information such as respondents' language and qualifications as well as their research activity; the second asks about use of CPUT research support services inside and outside the library and also asks for reactions to a list of possible services, garnered from the literature; the third section comprises a series of Likert scale statements which probe views on the library research services; the final section invites open-ended comment.

A stratified sample aimed at fair representation across all six faculties. Postgraduate students who were not CPUT staff members were excluded. Because responses to library questionnaires had been found to be low in the past, it was decided to send the questionnaire by email to the entire population of 602 academic staff. One hundred and two responses (17\% of the total population) were received as shown in Table I. This was deemed to be acceptable although the low response rate of the Applied Sciences Faculty, despite a second request being sent out, has to be noted.

Table I Study sample

\begin{tabular}{|l|c|c|c|c|}
\hline Faculty & $\begin{array}{c}\text { Academic staff in } \\
\text { each faculty }\end{array}$ & $\begin{array}{c}\text { No. of } \\
\text { respondents }\end{array}$ & $\begin{array}{c}\text { Percentage of } \\
\text { faculty total }\end{array}$ & $\begin{array}{c}\text { Percentage } \\
\text { of sample }\end{array}$ \\
\hline Applied Sciences & 68 & 5 & $7 \%$ & $5 \%$ \\
\hline Business & 160 & 18 & $11 \%$ & $18 \%$ \\
\hline Education & 74 & 14 & $19 \%$ & $14 \%$ \\
\hline Engineering & 150 & 23 & $15 \%$ & $23 \%$ \\
\hline Health \& Wellness & 40 & 12 & $30 \%$ & $12 \%$ \\
\hline Informatics \& Design & 110 & 22 & $20 \%$ & $22 \%$ \\
\hline Other (in units outside faculty structures) & - & 8 & - & $6 \%$ \\
\hline Total & 602 & 102 & $17 \%$ & $100 \%$ \\
\hline
\end{tabular}




\section{Findings}

This section provides analysis of the responses to the questionnaire. Not all respondents answered every question, hence occasional differences in totals $(\mathrm{N})$ in the tables and figures. Respondents were invited to add free comment at the end of the questionnaire. These comments are referred to where appropriate as they enrich the quantitative analysis.

\subsection{Respondents' personal information and research activities}

Figure I summarises respondents' job titles. The proportions are in keeping with academic staff patterns at CPUT. The eleven who replied "other" describe themselves as Heads of Department.

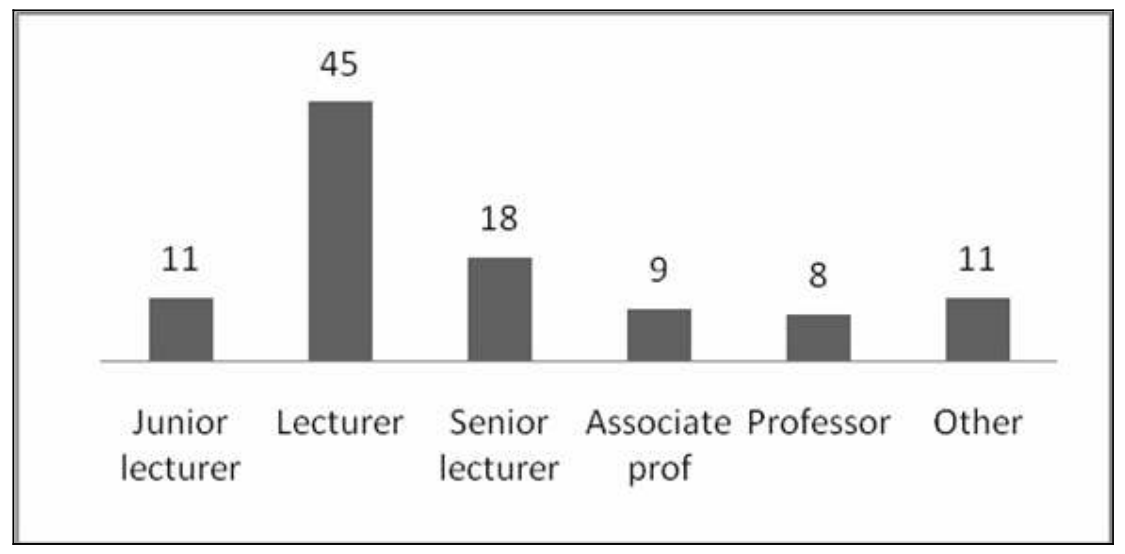

Figure 1 Respondents' positions $(\mathrm{N}=102)$

Table 2 reveals that English is the dominant home language. The low number of IsiXhosa speaking respondents might reflect patterns among researchers throughout South Africa. The need to diversify South Africa's research cohort was alluded to earlier. However, male and female numbers are more even, with 54 (53\%) of the 102 respondents being female. The median age is 50 years.

Table 2 Respondents' home language $(\mathrm{N}=102)$

\begin{tabular}{|l|l|}
\hline Afrikaans & 29 \\
\hline English & 54 \\
\hline IsiXhosa & 4 \\
\hline Other & 15 \\
\hline Total & 102 \\
\hline
\end{tabular}

The roots of CPUT in technical and vocational education, as described earlier, might explain the rather high numbers of respondents without $\mathrm{PhDs}$ and the $20 \%$ with qualifications lower than a Masters degree - as shown in Figure 2 . It can be assumed that doctoral research must be a priority among CPUT staff at present.

The next few questions gathered data on respondents' research activities. Eighty-nine (87\%) claimed to be involved in a research project at the time of the survey. Figure 3 provides an analysis of the projects.

An academic's job comprises teaching, administration and research. There is consensus among respondents that research is important: with 91 (89\%) and 92 (92\%) agreeing with the statements in Section 3 of the questionnaire that CPUT needs to build up its research culture and that research is essential to their jobs. However, the response to the question that asks respondents to estimate how much time they spend on research in their working year is on average $23.4 \%$. The median time is $20 \%$; thus, half of respondents claim to spend only about one fifth of their working year on research.

As pointed out in an earlier section, the major output for university research is scholarly publication. It is the means to disseminate research findings, add to knowledge and bolster the standing of the researcher's home institution. CPUT, in common with other South African UoTs, still lags behind the established research universities in terms of national research benchmarks, as is evident in the low numbers of publications in peer reviewed accredited journals reported by respondents in this study, as shown in Figure 4. The fact that so many of the CPUT respondents are engaged in formal 
degree work might explain the low numbers. The Figure shows that 54 have published nothing. The fact that 17 chose not to reply to the question might indicate that they could be added to this category.

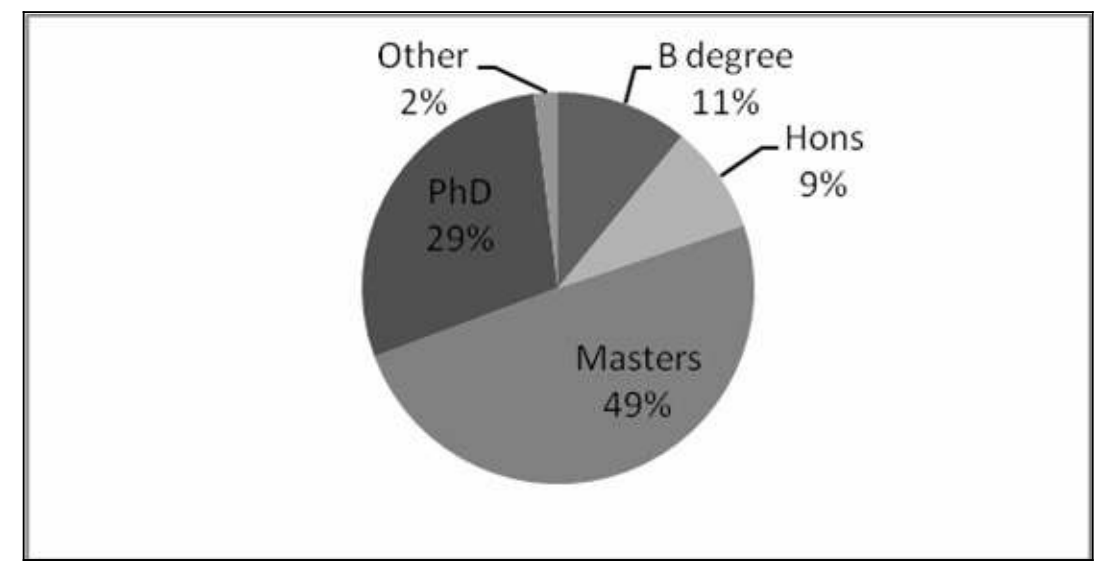

Figure 2 Highest formal qualification $(\mathrm{N}=102)$

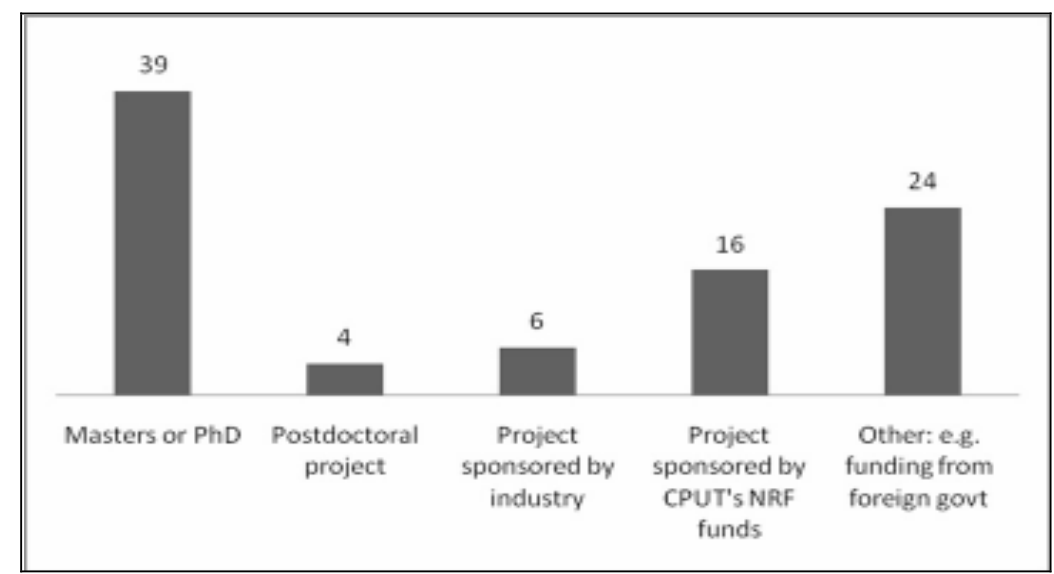

Figure 3 Current research projects $(\mathrm{N}=89)$

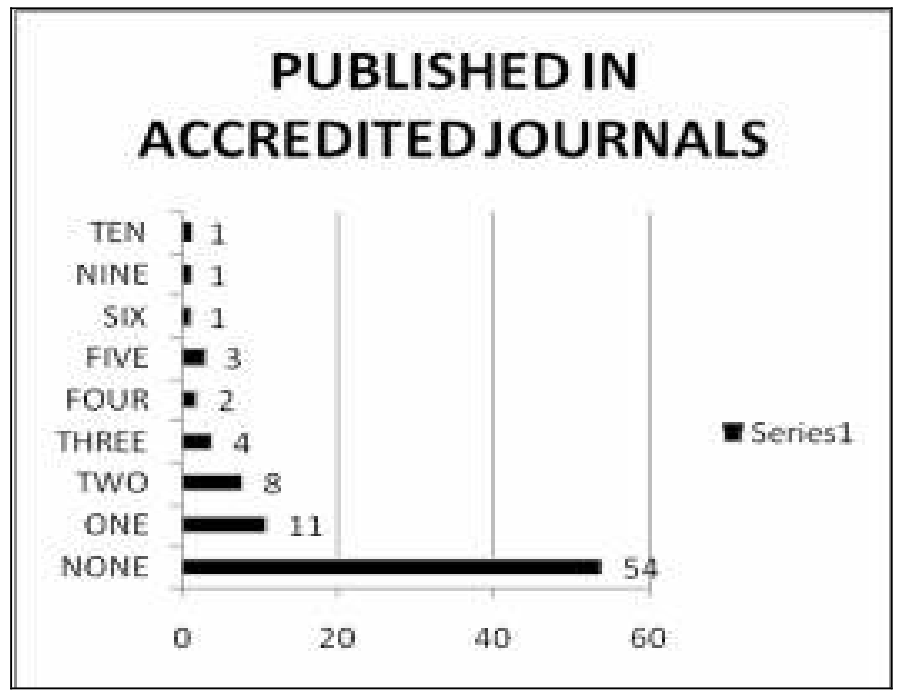

Figure 4 Articles published in accredited journals in last 3 years $(\mathrm{N}=85)$ 
Several respondents comment later in the final open-ended question that they just do not have time for research because of heavy teaching workloads, for example:

"I agree library and research important, but teaching is equally important. There is not enough time to do both adequately."

"I would love to do formal research but the requirements of our industry stakeholders mean that a specialist like myself needs to be in the classroom because there is no backup to teach my subject."

The dilemma revealed in this second quotation is probably shared by many of his or her colleagues across South African UoTs. It stems from their history as vocational training institutions with strong ties with industry.

5.2 Researchers' use of and perceptions of the library

Section B of the questionnaire focuses on respondents' use of and perceptions of the library in their research. Table 3 indicates the use of the various research support services at CPUT in the past year. The library has the most use.

Table 3 Research support services used in past year $(\mathrm{N}=89)$

\begin{tabular}{|l|c|}
\hline CPUT research support services in the past year & No. of responses \\
\hline Library (in general) & 81 \\
\hline Fundani (the teaching and learning support centre for academics) & 22 \\
\hline Centre for Postgraduate Studies & 19 \\
\hline RISC & 14 \\
\hline Other & 6 \\
\hline Research Directorate & 5 \\
\hline
\end{tabular}

Table 4 indicates the use of specific library services in the past year. The most popular service is "access to databases and other e-resources" with the borrowing of materials and interlibrary loan services next. The responses are in keeping with trends reported in international research, as outlined in a previous section. For example, the low use of library database training, a major focus of the library's information literacy programmes, might indicate the differences in perspectives between librarians and researchers that were found in the major study in the UK in 2007, Researchers' Use of Academic Libraries and Their Services.

Table 4 Library services used for research in the past year $(\mathrm{N}=92$ : multiple responses were possible)

\begin{tabular}{|l|c|}
\hline Library services used for research & No. of responses \\
\hline Library e-resources & 73 \\
\hline Borrowed library print resources & 55 \\
\hline Inter-library loans & 52 \\
\hline Faculty Librarian's reference/information services & 32 \\
\hline Attended a training workshop on databases & 22 \\
\hline Library quiet study area & 7 \\
\hline Other & 2 \\
\hline Total & 243 \\
\hline
\end{tabular}

Table 4 shows that 32 respondents claim to have consulted their faculty librarians, professional staff designated to serve staff and students of specific faculties, in the past year. A follow up question reveals that the frequency of consulting library staff varies enormously, with eight reporting more than 25 interactions with a librarian (not only their faculty librarians) about their research in the past year. The median number of contacts is three. This finding might raise questions about the evenness of librarian services across the eight campuses and six faculties.

Responses to the next two questions throw further light on this issue. They ask respondents firstly to rate the library's support for their research on a scale of "non-existent" to "indispensable", then to explain any low rating using a list of possible reasons. The average score from the 96 responses is 5.9 out of 10 , thus just below "good". 


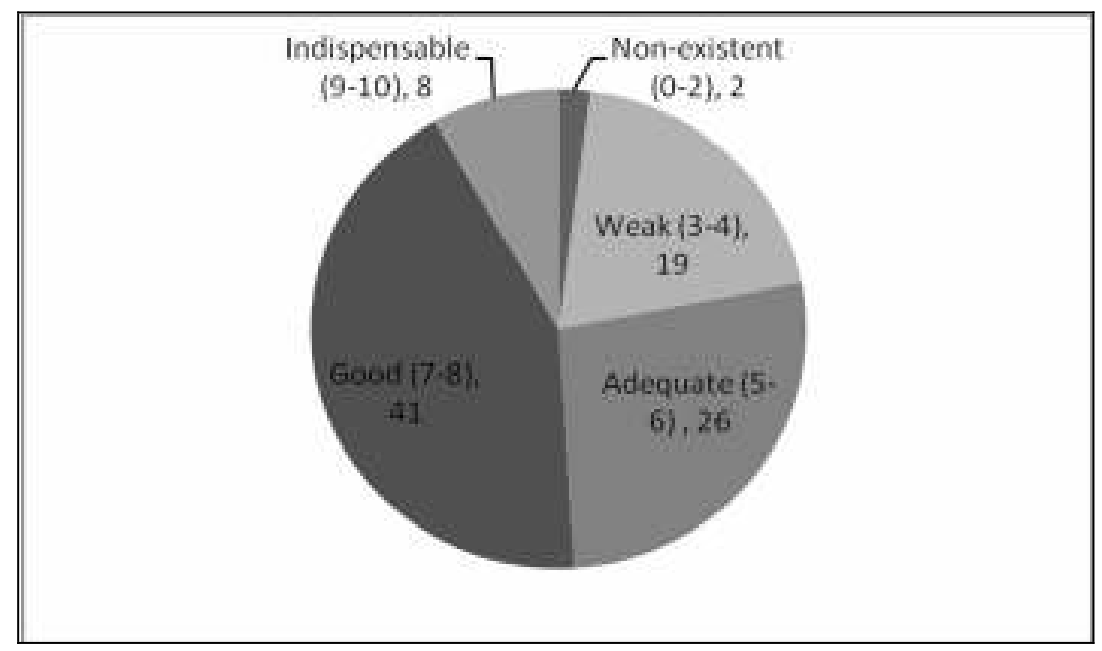

Figure 5 Rating of library research support $(\mathrm{N}=96)$

Table 5 gives the results of the cross tabulation of respondents' ratings and their faculty. It reveals that all but one of the 13 respondents in the Education Faculty rate the library as "good" or "indispensable". Eight (37\%) of the "non existent" and "weak" ratings come from the respondents in the Informatics \& Design Faculty and 7 (30\%) from the 23 Engineering Faculty respondents. However, the fact that 10 (44\%) of the "good" and "indispensable" scores also come from the Engineering Faculty points to the risks in making conclusions from such low numbers.

Table 5 Ratings by faculty $(\mathrm{N}=96)$

\begin{tabular}{|l|c|c|c|c|c|c|}
\hline Faculty & Non existent & Weak & Adequate & Good & Indispensable & Total respondents \\
\hline Applied Sciences & & $\mathrm{I}$ & $\mathrm{I}$ & 3 & & 5 \\
\hline Business & $\mathrm{I}$ & 2 & 6 & 7 & $\mathrm{I}$ & 17 \\
\hline Education & & $\mathrm{I}$ & & 9 & 3 & 13 \\
\hline Engineering & & 7 & 4 & 8 & 2 & 21 \\
\hline Health \& Wellness & & $\mathrm{I}$ & 6 & 3 & $\mathrm{I}$ & $1 \mathrm{I}$ \\
\hline Informatics \& Design & $\mathrm{I}$ & 7 & 6 & 7 & & 21 \\
\hline Not attached to one faculty & & & 3 & 4 & 1 & 8 \\
\hline Total & 2 & 19 & 26 & 41 & 8 & 96 \\
\hline
\end{tabular}

Table 6 provides insight into the problems researchers might be experiencing as it summarises the reasons given for low ratings as selected from a list of possible answers, from most commonly cited to least. Respondents ticked more than one and seven other reasons were given under the heading "other".

The relatively strong comment on the inadequacy of library research collections has to be viewed in the light of the history of UoTs as vocational education institutions as discussed in the introduction. As mentioned earlier, international research confirms the ongoing importance to researchers in all disciplines of access to archival and current collections and it might be assumed that UoTs might now be prioritising their research collections. This study made no attempt to assess the CPUT library collections but it did ask respondents how many books for their research they had requested for the library in the past year. Responses reveal that half had ordered none. The average number is 13 . Three researchers claim to have ordered 500, 120 and 50 books respectively.

Still probing respondents' views of the role of the library in their research, the questionnaire went on to ask them to rate a list of possible services, garnered from the literature, as "very important" "useful" or "not important". Table 7 lists the result in order of most importance to least. In keeping with other studies, it seems that the most valued services are still the traditional current awareness services of academic libraries. The high value put on database training contradicts the earlier finding on the low use of the library's programme of database training workshops. It could be that researchers prefer "just-in-time" individual coaching rather than scheduled workshops. Given the lack of take-up of CPUT's fledging research repository the high value given to it suggests the need for some follow-up work by the library. 
Table 6 Reasons for low rating $(\mathrm{N}=2 \mathrm{I})$

\begin{tabular}{|l|c|}
\hline Reasons for low rating & No. of responses \\
\hline Network / databases too slow & 14 \\
\hline Collection in my area is not adequate & 12 \\
\hline Inter-library loan services take too long & 10 \\
\hline Librarians lack subject knowledge & 7 \\
\hline Faculty librarians are too busy & 4 \\
\hline Librarians know very little about research & 3 \\
\hline Library acquisition budget is too small & 3 \\
\hline $\begin{array}{l}\text { Other } \\
\text { "I can't access library databases off-campus" } \\
\text { "Lack of professional engineering journals especially IEEE” } \\
\text { "[No] direct access to digital scholarly sources \& digital scholarly journals to which I subscribe” } \\
\text { "[My] subject Law is not mainstream" } \\
\text { “Impossible to get advice - e.g Refworks" } \\
\text { "New books take too long” }\end{array}$ \\
\hline
\end{tabular}

Table 7 "Wish list" of library research support services

\begin{tabular}{|l|l|}
\hline Ranking & “Wish list" of library research support services \\
\hline 1 & Ongoing updates on new information resources \\
\hline 2 & Maintaining of research repositories \\
\hline 3 & Database training \\
\hline 4 & Providing a reading list on my topic \& providing advice on my literature review \\
\hline 5 & Advice on bibliographic referencing \\
\hline 6 & Advice on my research topic \\
\hline 7 & Advice on research proposal writing \\
\hline
\end{tabular}

\subsection{Likert scale statements}

Figure 6 presents the responses to a series of six Likert scale statements which were designed to probe respondents' views further and to confirm the findings of some of the earlier questions.

Some positive support for the role of the library in research is evident, perhaps suggesting a better rating than the "adequate" average of 5.9 given in reply to an earlier question. There is fairly strong agreement that the library's collection and resources can support research needs (66\%), although the inadequacy of collections was identified as a problem in Table 6. It seems that the library continues to play a role in the changing electronic environment with 66 $(65 \%)$ saying that e-resources have not made the physical library redundant and 74 (73\%) saying that the Internet has not replaced their use of the library. These figures lend support to the earlier finding on the recognition of the value of the library's managing of access to e-resources.

However, only 23 respondents (22\%) report that librarians are updating them with relevant information and only 42 (4I\%) believe unequivocally that librarians have adequate subject knowledge. Cross tabulation reveals that the strongest doubt over librarians' subject knowledge lies among respondents in the Engineering and Informatics and Design faculties, which might be understandable given the technical nature of their disciplines and possible challenges in finding library staff with related qualifications. The question of librarians' capacity for a stronger role than merely finding and managing information is debated in the literature. It was one of the questions that divided librarians and researchers in the RIN study, Researchers' Use of Academic Libraries and Their Services (Brown \& Swan 2007), that was described earlier. Librarians' capacity in terms of their subject knowledge and their knowledge of research methodologies is a major focus of the South African Research Libraries Consortium's academy, as mentioned in an earlier section. The comment added by one CPUT respondent that "no advice on my literature analysis is needed. [I'm an] experienced researcher" might well serve to focus librarians' minds on what their role in support of research is. 


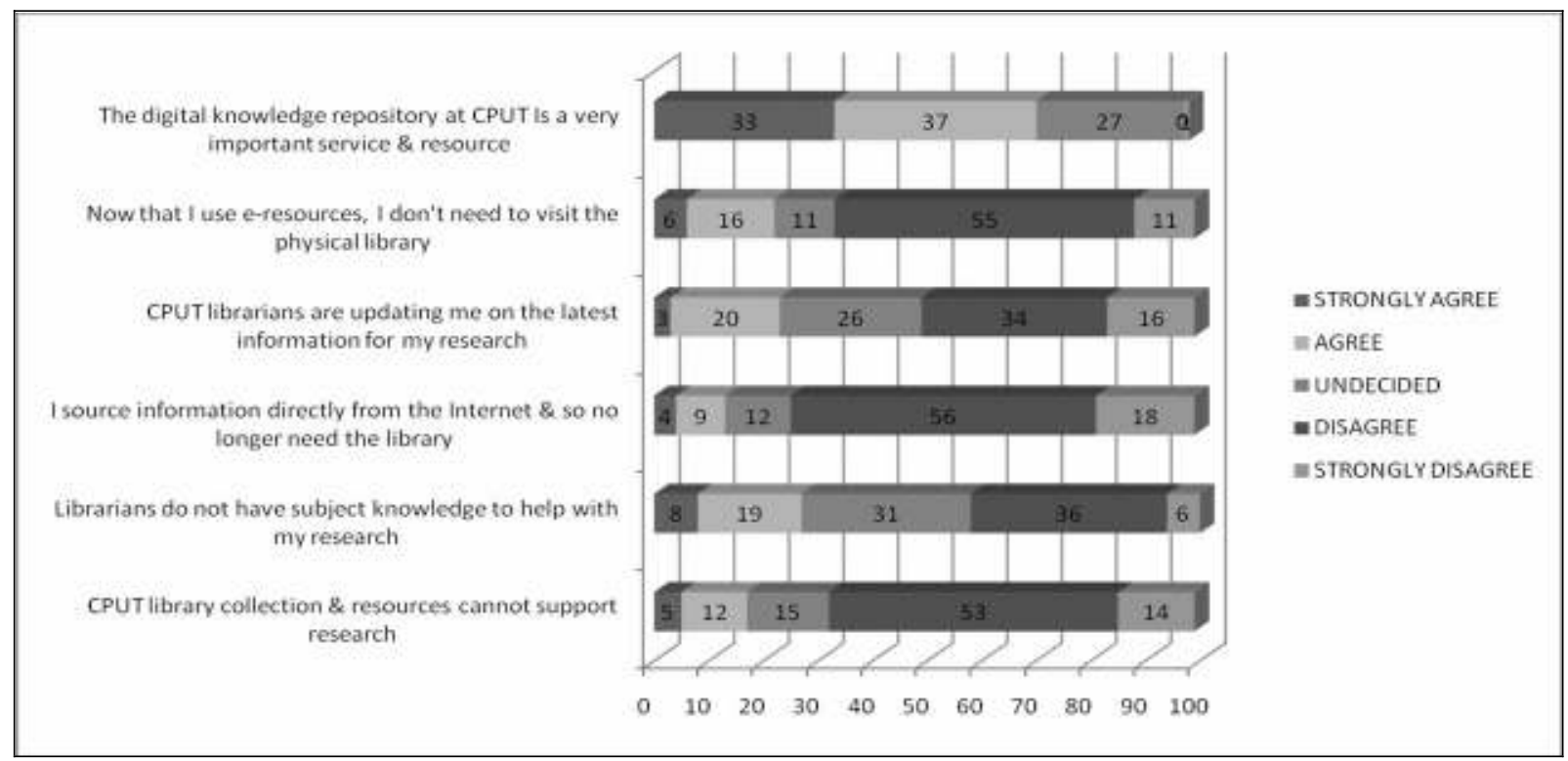

Figure 6 Responses to Likert scale statements

One role that has emerged recently in the academic library literature is a more active part in the publishing and disseminating of a university's research through the management of institutional repositories. Responses from the CPUT respondents in an earlier question suggested recognition of this as an important responsibility of the library and $69 \%$ confirm this in response to the Likert scale statement on CPUT's repository, Digital Knowledge. However, some added free comment suggests some uncertainty, for example:

"Digital knowledge? I do not know what this is. If journal then "yes"."

"I am not even aware of the Digital Knowledge repository. The library should showcase and/or advertise these resources."

"Digital knowledge - I never heard of this. What is it?"

\section{Discussion of findings}

The analysis of the responses in the preceding section gives insights into firstly respondents' research profiles and then of their perceptions of the library with regards to research support. Cross tabulations suggest that there might well be some differences among faculties in terms of responses. But statistical tests of significance would be needed to confirm this suggestion. One problem might be the low representation of the Applied Sciences Faculty.

The study has other limitations. One is that it excluded postgraduate students of the university. Another is that it looked only at the library related behaviour of researchers and did not gather data on their use of other communication channels, such as open access journals, online alerting services and virtual communities of practice.

Although over $90 \%$ of respondents agree that research is essential to their job and that CPUT needs to build a stronger research culture, the challenges specific to universities of technology in South Africa are shown in the findings that:

- The average time percentage spent in a working year on research is only $23.4 \%$. Several comments in the final openended question suggest that heavy teaching workloads are to blame.

- $65 \%$ of respondents have not published any articles in accredited journals in the past three years.

- Research towards doctoral and Masters degrees dominates.

Perhaps unsurprisingly, the three library services being most extensively used are access to e-resources, borrowing print resources and inter-library loan services. Most respondents make some use of the library in their research; but far fewer ever consult a librarian. The number one on researchers' wish lists for library research support services is to be kept informed of new research in their field. But the study uncovers some doubt, perhaps specific to certain disciplines, over librarians' capacity for this work in terms of their subject knowledge. The comment provided in the preceding section from an experienced researcher that he or she needs no help with "analysis" might perhaps be seen as a warning to librarians wishing to extend their services beyond information and resources management. In the introduction to this 
article, reference was made to the "testing" of the relationship of researchers and libraries by the rise of desktop access to digital information. Easy access to online communities of practice and alerting services, for example, is negating the need for what might be called the "gateway" services of libraries, especially it seems in the sciences. One strategy to narrow the gap between librarian and researcher has been to locate library staff as "informationists" inside academic departments or research units (Schonfeld \& Housewright 2010: 9). But this requires a reconceptualisation and restructuring of academic library services, which might be beyond the means of a South African university of technology.

CPUT libraries might consider the comment, alluded to earlier, on the renewed interest among academics in the United States in the teaching support role of libraries and how this might build the relationships required for a more active role in research (Schonfeld \& Housewright 2010: 10). In the absence of school libraries, the average South African university entrant is underprepared for the demands of university study and arguably the library's teaching role must be even more valuable. The library's RISC, a unit designated for postgraduate learning, might well serve to bridge teaching and research support.

The fairly strong support among the CPUT respondents for the role of the Digital Knowledge Repository confirms the value of this library project, which should grow in importance as the university expands its research output. The expertise of academic libraries in information management is invaluable in the electronic research environment. Researchers look to librarians to lead in the organizing and archiving of data sets and other research output (Brandt 2007: 365).

\section{Conclusion}

The premises of the study at CPUT were that, if South Africa is to progress to a knowledge society, its universities will have to increase research output and that UoTs have a particularly important role to play. Therefore their libraries have a special responsibility to support their efforts to improve their research culture and output.

The study provides positive news in that the library is revealed as playing a significant role in research. However, it will be important for the library to anticipate shifts in researcher information seeking and sharing behaviour. International experience suggests that researchers will use the library less and less for information discovery but will rely on its expertise in organizing and archiving their research output.

\section{References}

Association of Southeastern Research Libraries (ASERL). 200I. Shaping the future: ASERL's competencies for research librarians. [Online]. http://www.aserl.org/statements/competencies/competencies.pdf (Accessed 23 February 2009).

Blaine, S. 2010. Government to overhaul funding of research. Business Day, 23 March 2010. [Online]. http://allafrica.com/stories/ 201003230072.html (Accessed 23 March 2010).

Brandt, D S. 2007. Librarians as partners in e-research: Purdue University Libraries promote collaboration. College and Research Libraries News, 68 (6): 365-376, 396.

Brown, S. and Swan, A. 2007. Researchers' use of academic libraries and their services. A report commissioned by the Research Information Network and the Consortium of Research Libraries. London: RIN \& CURL. [Online]. http://eprints.ecs.soton.ac.uk/ (Accessed 16 October 2007).

Canadian Association of Research Libraries. 2010. Core competencies for 2 Ist century CARL librarians. [Online]. http://www.carlabrc.ca/resources/reports_and_briefs/pdf/core_comp_profile-e.pdf (Accessed 16 November 2010).

Cape Peninsula University of Technology. 2006. The vision, mission and strategic plan of the Cape Peninsula University of Technology. [Online]. http://www.cput.ac.za/institution/. (Accessed 28 July 2008).

Coetzee, J.A. 2007. Strategic plan for 2007 of the Academic Information Services (AIS) of the Cape Peninsula University of Technology. Unpublished report. Cape Town: Cape Peninsula University of Technology.

Department of Science and Technology. 2010. National survey of research and experimental development (2008/09 Fiscal Year). Pretoria: HSRC \& DST. [Online]. http://www.dst.gov.za/publications-policies/r-d-reports/R-D\%20Survey\%20Results\%20200809\%20Revised.pdf (Accessed 30 March 20I I).

Du Pré, R. 2009. The place and role of universities of technology in South Africa. Bloemfontein: South African Technology Network.

Dulle, F W; Lwehabura, MJ F; Mulimila, R T. and Mato, D S. 200I. Researchers' perspectives on agricultural libraries as information sources in Tanzania. Library Review. 50(4): 187-192.

Fan, K W. 2005. The role of university libraries in supporting research in Hong Kong: facing a new challenge. Campus Wide Information Systems, 22(I): 43-50.

Frascati manual. 2002. Proposed standard practice for surveys on research and experimental development. $6^{\text {th }}$ ed. Paris: Organisation for Economic Co-operation and Development.

Garner, I. 2006. Library support for research in a university context. 27th IATUL CONFERENCE Embedding Libraries in Learning and Research Oporto, Portugal, May 22-25 2006. [Online]. http://arts.fe.up.pt/use/extra/iatul_v/6/proceedings/ FinalPapers/iatul_vl6_fps_2_2.pdf. (Accessed 23 February 2009).

Hamblin, Y. 2005. Library portals case studies. Assignation, 22(3): 26-29.

Maserumule, M.H. 2005. Designating technikons universities of technology in South Africa: implications for public management education. African Journal of Public Administration and Management, I6(I): I4-27.

Mgobozi, M.N. and Ocholla, D.N. 2002. The use of electronic journals for the dissemination of scholarly information by the University of $\mathrm{Natal}$ and the University of Zululand. South African Journal Of Libraries and Information Science, 68(2): 8I-93.

SA Jnl Libs \& Info Sci 20II, 77(I) 
Miller, F. 2008. Research information needs of public policy oriented researchers at a regional university: issues emerging from a pilot study. Australian Academic and Research Libraries, 39(4): 253-268.

Ortiz-Repiso, V, Bazán, V, Ponsati, A. and Cottereau, M. 2006. How researchers are using the OPAC of the Spanish Council for Scientific Research library network. Electronic library, 24(2): 190 - 2 I I.

Research Libraries Consortium (Universities of Cape Town, KwaZulu-Natal and Witwatersrand). 2007. Summary information sheet. Unpublished report.

Schonfeld, R C. and Housewright, R. 2010. Ithaka S + R faculty survey 2009: key strategic insights for libraries, publishers, and societies. New York: Ithaka S + R. [Online]. http://www.ithaka.org/ithaka-s-r/research/faculty-surveys-2000-2009/ Faculty\%20Study\%202009.pdf (Accessed 2I February 2010).

The Value of libraries for research and researchers: a RIN and RLUK report. 20I I. London: Research Information Network and Research Libraries UK. [Online]. http://www.rin.ac.uk/our-work/using-and-accessing-information-resources/value-librariesresearch-and-researchers (Accessed $2 \mathrm{I}$ March 20II).

Van Aswegen, E S. (ed). 2010. Cape Peninsula University of Technology research report 2009. Cape Town: CPUT Research Directorate. [Online]. http://dk.cput.ac.za/res_papers/9 (Accessed 16 November 2010).

Van Zijl, CW. 2005. Developing and managing information collections for academics and researchers at a university of technology: a case study. PhD Thesis, University of South Africa.

Webb, J., Gannon-Leary, P. and Bent, M. 2007. Providing effective library services for research. London: Facet.

Weintrob, J. 20I I. CPUT leads the UoT field as research outputs surge. CPUT news I8/02/20I I. [Online] http://info.cput.ac.zal News/news.php?aid=966 (Accessed 30 March 201 I). 